\title{
Gene-Specific Methylation Analysis in Thymomas of Patients with Myasthenia Gravis
}

\author{
Angela Lopomo ${ }^{1,2}$, Roberta Ricciardi ${ }^{3,4}{ }^{\text {, Michelangelo Maestri }}{ }^{3}$, Anna De Rosa ${ }^{3}$, Franca Melfi ${ }^{4}$, \\ Marco Lucchi ${ }^{4}$, Alfredo Mussi ${ }^{4}$, Fabio Coppedè ${ }^{1, *}$ and Lucia Migliore ${ }^{1}$ \\ 1 Department of Translational Research and New Technologies in Medicine and Surgery, \\ Division of Medical Genetics, University of Pisa, Medical School, Via Roma 55, 56126 Pisa, Italy; \\ angela.lopomo@student.unisi.it (A.L.); lucia.migliore@med.unipi.it (L.M.) \\ 2 Department of Medical Biotechnologies, University of Siena, 53100 Siena, Italy \\ 3 Department of Clinical and Experimental Medicine, Neurology Unit, University of Pisa, Medical School, \\ Via Roma 55, 56126 Pisa, Italy; r.ricciardi@ao-pisa.toscana.it (R.R.); michelangelo.mvg@tin.it (M.M.); \\ annu.derosa@hotmail.it (A.D.R.) \\ 4 Division of Thoracic Surgery, Cardiothoracic and Vascular Surgery Department, University of Pisa, \\ Medical School, Via Roma 55, 56126 Pisa, Italy; franca.mamelfi@gmail.com (F.M.); \\ marco.lucchi@unipi.it (M.L.); a.mussi@dc.med.unipi.it (A.M.) \\ * Correspondence: fabio.coppede@med.unipi.it; Tel.: +39-50-221-8544; Fax: +39-50-221-0624 \\ Academic Editor: Li Yang \\ Received: 11 November 2016; Accepted: 12 December 2016; Published: 16 December 2016
}

\begin{abstract}
Thymomas are uncommon neoplasms that arise from epithelial cells of the thymus and are often associated with myasthenia gravis (MG), an autoimmune disease characterized by autoantibodies directed to different targets at the neuromuscular junction. Little is known, however, concerning epigenetic changes occurring in thymomas from MG individuals. To further address this issue, we analyzed DNA methylation levels of genes involved in one-carbon metabolism (MTHFR) and DNA methylation (DNMT1, DNMT3A, and DNMT3B) in blood, tumor tissue, and healthy thymic epithelial cells from MG patients that underwent a surgical resection of a thymic neoplasm. For the analyses we applied the methylation-sensitive high-resolution melting technique. Both MTHFR and DNMT3A promoters showed significantly higher methylation in tumor tissue with respect to blood, and MTHFR also showed significantly higher methylation levels in tumor tissue respect to healthy adjacent thymic epithelial cells. Both DNMT1 and DNMT3B promoter regions were mostly hypomethylated in all the investigated tissues. The present study suggests that MTHFR methylation is increased in thymomas obtained from MG patients; furthermore, some degrees of methylation of the DNMT3A gene were observed in thymic tissue with respect to blood.
\end{abstract}

Keywords: thymoma; myasthenia gravis; cancer; epigenetics; DNA methylation; MTHFR; DNMT3A

\section{Introduction}

Thymomas are uncommon neoplasms that arise from epithelial cells of the thymus and are often accompanied by non-neoplastic lymphocytic proliferation. On the basis of the morphology of epithelial cells and the lymphocyte to epithelial cell ratio, they are classified into five histological types, $\mathrm{A}, \mathrm{AB}$, B1, B2, and B3 [1]. The most widely used system for staging thymomas is the Masaoka-Koga staging system; according to this, thymomas are classified in stage I comprising encapsulated tumors, stages II and III showing direct local invasion, and stage IV showing metastatic spread [2]. Thymomas are associated with a wide variety of autoimmune diseases, and among these about $30 \%-40 \%$ of thymomas are associated with myasthenia gravis (MG), an autoimmune disease characterized by autoantibodies directed to different targets at the neuromuscular junction, such as acetylcholine receptor (AChR), muscle specific kinase (MuSK), and agrin-receptor low-density lipoprotein receptor related-protein 4 
(LRP4) [3]. Almost all thymoma-associated MG (TAMG) patients have antibodies to the AChR; very rare exceptions have been seen in anti-MuSK + or in double seronegative patients, while anti-LRP4 autoantibodies have not been reported [4]. The molecular events that characterize thymic neoplasms, including point mutations, chromosomal aberrations, and epigenetic modifications, such as changes in DNA methylation, have been described in the last few years [5]. Aberrant DNA methylation is the most widespread epigenetic alteration in carcinogenesis, and consists of the addition of a methyl group to cytosines, mainly in a CpG dinucleotide context, leading to gene silencing when occurring in the promoter region of a gene [6]. The reversibility of epigenetic changes, unlike genetic modifications, makes them a therapeutic target since, for instance, demethylating drugs can re-express genes silenced by methylation [7].

Concerning thymomas, the silencing of tumor suppressor genes, such as FHIT, MLH1, and E-cad, by DNA promoter methylation, has been described [8]. Aberrant methylation of other genes such as $M G M T, C D K N 2 A, H P P 1$, and DAP-K, associated with the loss of protein expression, was observed [9]. Interestingly, promoter methylation of the CDKN2A gene was reported in up to $11 \%$ of thymomas and $25 \%$ of thymic carcinoma [10], while aberrant MGMT methylation and loss of its protein expression was more frequent in thymic carcinoma than in thymoma [11].

Folate metabolism plays an important role in the methylation process as it provides one-carbon units for both purine and pyrimidine base synthesis or for the formation of $S$-adenosylmethionine (SAM), the universal donor of methyl groups, thus playing an important role in DNA or RNA synthesis and repair, and in DNA methylation processes [12]. A key role in this metabolism is provided by methylenetetrahydrofolate reductase (MTHFR), the enzyme that catalyzes the reaction, which directs the provision of methyl groups donated from folate cofactors towards the remethylation of homocysteine to methionine; this last produces SAM, which is then used by DNA methyltransferases (DNMTs) that transfer the methyl group from SAM to the DNA. As a consequence, folate deficiency can disrupt DNA integrity and promote carcinogenesis [13]. DNMT1 is primarily involved in the maintenance of DNA methylation patterns during development and cell division, whereas DNMT3A and DNMT3B are the de novo methyltransferases that establish DNA methylation patterns during early development [14]. Given supportive evidence from the literature of the contributions of aberrant methylation and expression of MTHFR and DNMTs, such as DNMT1, DNMT3A, and DNMT3B, in other types of cancer, such as those of the breast, lung, and brain [15-17], we performed the present study to evaluate the methylation levels of these genes in thymomas of patients with MG.

\section{Results}

\subsection{Methylation Levels among Tissues}

Table 1 shows the mean methylation levels of the MTHFR, DNMT3A, DNMT3B, and DNMT1 genes in blood and tumor tissue DNA of all TAMG patients. MTHFR shows higher methylation levels in tumor tissue respect to blood $(p=0.007)$, and DNMT3A shows about $10 \%$ promoter methylation in tumor tissue but is completely demethylated in blood $(p<0.0001)$. DNMT3B and DNMT1 studied regions were largely hypomethylated both in blood and tumor tissue DNA.

Table 1. Methylation levels (\%) of the studied genes in blood and tumor tissue of total thymoma-associated MG (TAMG) patients $(n=69)$. Blood and tumor tissues were taken from the same donors, and the $p$-value refers to a $t$-test for paired samples.

\begin{tabular}{cccc}
\hline Gene & Blood (Mean \pm SEM) & Tumor Tissue (Mean \pm SEM) & $p$-Value \\
\hline MTHFR & $24.28 \pm 0.99$ & $29.66 \pm 1.55$ & 0.007 \\
DNMT3A & $0.35 \pm 0.08$ & $9.78 \pm 0.91$ & $<0.0001$ \\
$D N M T 3 B$ & $1.14 \pm 0.24$ & $0.95 \pm 0.26$ & 0.408 \\
DNMT1 & $1.67 \pm 0.12$ & $1.43 \pm 0.13$ & 0.041 \\
\hline
\end{tabular}


Figure 1 shows the mean methylation levels of the studied genes in blood, tumor tissue, and thymic epithelial tissue adjacent to the cancer, in the 44 patients for whom adjacent tissue was available. MTHFR shows higher methylation levels in tumor tissue with respect to blood $(p=0.0053)$ and to adjacent tissue $(p<0.001)$. DNMT3A shows higher methylation levels in tumor tissue and adjacent thymic tissue with respect to blood that results in them being completely demethylated $(p<0.001)$, but no significant difference was observed between thymomas and adjacent thymic tissue. The other two genes, DNMT3B and DNMT1, show very low methylation levels, no more than $2 \%$, and no statistically significant difference was observed among the studied tissues. Age, gender, and clinico-pathological features had no effect on the mean methylation levels of the studied genes (Table S1).
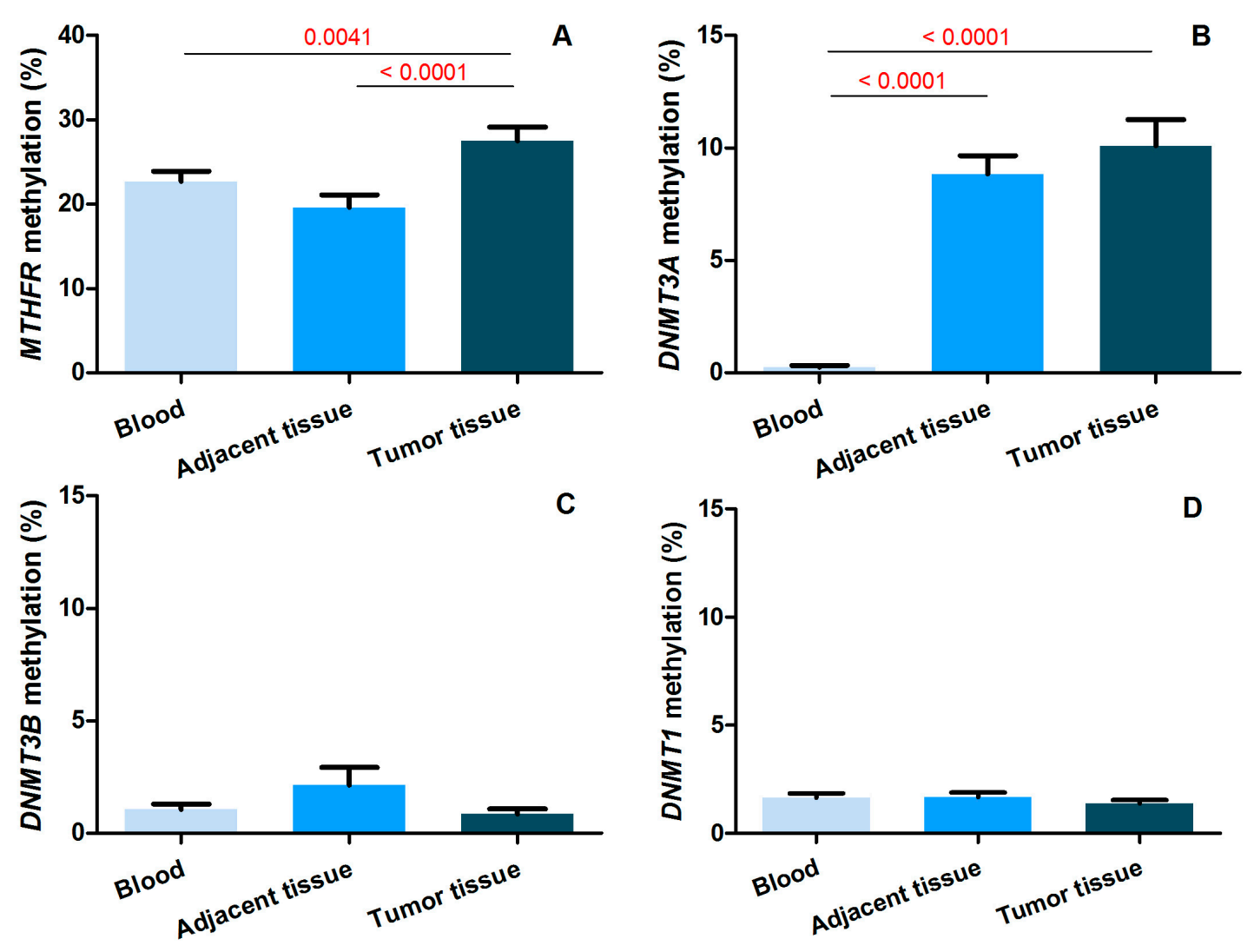

Figure 1. Methylation levels (\%) of the studied genes ((A) MTHFR; (B) DNMT3A; (C) DNMT3B; and (D) DNMT1) in blood, tumor tissue and adjacent thymic tissue of thymoma-associated MG (TAMG) patients for whom adjacent tissue was available $(n=44)$. The significant $p$-values (in red) refer to $t$-tests for paired samples.

\subsection{Correlation of Methylation Levels among Tissues}

Interesting correlations between the MTHFR methylation levels among blood, tumor tissue, and thymic tissue adjacent to the tumor were observed (Figure 2A-C). In particular, correlation of MTHFR methylation levels between tumor tissue and blood was observed in the whole population (Figure 2A; $n=69 ; p=0.004, r=0.34$ ) Moreover, correlations between blood and thymic tissue adjacent to the tumor (Figure $2 \mathrm{~B} ; n=44 ; p=0.007, r=0.40$ ) and between tumor tissue and adjacent thymic tissue (Figure 2C; $n=44 ; p=0.002, r=0.45$ ) were observed. 

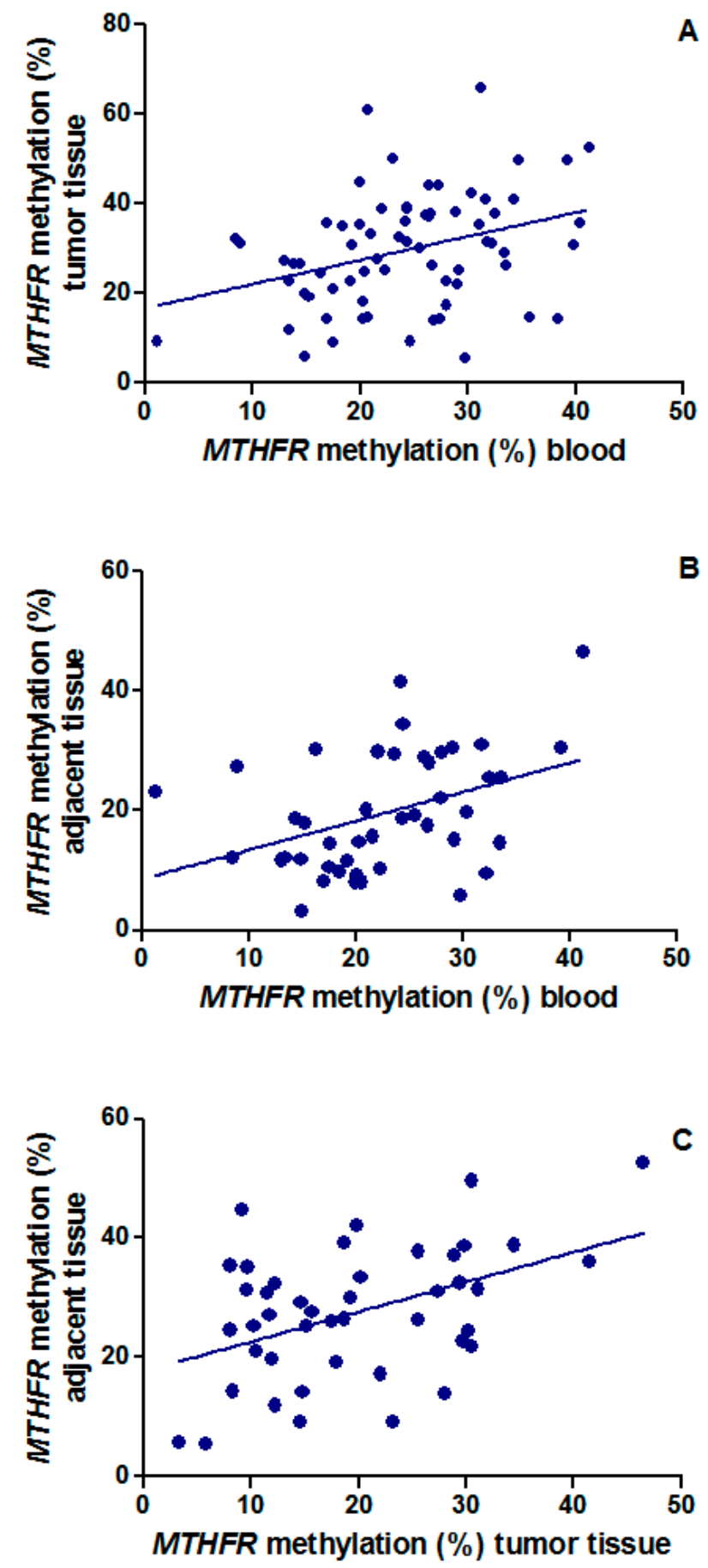

Figure 2. Correlation of MTHFR methylation levels (A) between tumor tissue and blood in the total population ( $r=0.34 ; p=0.004)$; (B) between adjacent tissue and blood ( $r=0.40 ; p=0.007)$; and (C) between tumor and adjacent thymic tissue $(r=0.45 ; p=0.002)$ in the subgroup of 44 individuals with available thymic tissue adjacent to the tumor; $r=$ Pearson's correlation coefficient.

\section{Discussion}

In the present study we investigated the methylation levels of genes involved in DNA methylation reactions, such as DNMT1, DNMT3A, and DNMT3B, and in one-carbon metabolism, MTHFR, in blood and tumor tissue DNA from 69 thymoma-associated myasthenia gravis patients; for 44 of them we also had thymic epithelial tissue adjacent to the tumor. We observed that MTHFR and DNMT3A promoters 
show different methylation levels between blood and tumor tissue; this data was observed in the total population composed of 69 patients as well as in the smaller subgroup of 44 patients for whom healthy thymic specimens were available. In the subgroup of 44 patients, different MTHFR methylation levels between the adjacent thymic tissue and the tumor tissue were noticed; in particular, tumor tissue showed on average higher methylation levels with respect to adjacent healthy tissue. For DNMT3A, higher methylation levels in the healthy tissue adjacent to a tumor were observed with respect to blood. Comparing the methylation levels of the studied genes in different tissues, statistically significant correlations of MTHFR promoter methylation levels between blood and tumor tissue, adjacent thymic tissue and blood, and tumor tissue and adjacent tissue were observed.

MTHFR is one of the major enzymes in folate metabolism since it catalyzes the irreversible conversion of 5,10-methylene THF (the methyl donor in the conversion of dUMP to dTMP) into 5-methyl THF, which remethylates homocysteine to methionine, necessary for the formation of $S$-adenosylmethionine, the universal donor of methyl groups; therefore, this key protein controls whether folate is partitioned towards DNA precursor synthesis or DNA methylation, and an alteration of this enzyme can interfere with the provision of methyl groups necessary for DNA methylation reactions. It is revealing that the MTHFR gene is regulated by promoter methylation and an increased MTHFR promoter methylation has been observed in several human diseases, such as cardiovascular and renal diseases [18,19], male infertility [20-22], and preeclampsia [23]. Moreover, it is also emerging that MTHFR hypermethylation could be involved in cancer formation; in fact, a correlation between MTHFR hypermethylation and lung cancer or cervical cancer lesions was observed [15,24].

In our cohort we observed higher MTHFR methylation levels in tumor tissue with respect to blood and adjacent thymic tissue, and we found a strong correlation between methylation levels in blood and tumor tissue. To our knowledge, this is the first time that MTHFR methylation has been analyzed in TAMG. We studied a CPG island previously associated with gene silencing; in fact, an inverse correlation was observed between the methylation levels of this region and gene expression levels, suggesting that hypermethylation of the MTHFR gene at the studied CPG sites may have a functional significance and may result in partial or complete silencing of the gene [15]. The silencing of MTHFR could cause a significant decrease in the global 5-methylcytosine content, leading to the activation of proto-oncogenes, as well as to global hypomethylation, as demonstrated in lung cancer by Vaissière and coworkers [15]. Furthermore, this can increase the availability of 5,10-methylene THF for the synthesis of thymidine and purine, causing the hyper-proliferation of cancerous cells. In this regard, it was suggested that MTHFR hypermethylation might confer a growth advantage to cancer cells and contribute to the cancer phenotype in tumors of the upper aero-digestive tract [25]. Moreover, MTHFR promoter methylation levels have been correlated with cancer risk factors and with markers of impaired folate metabolism, including tobacco smoking, low circulating folates and vitamin B12, high homocysteine levels, and increased chromosome instability [15,18,26,27].

This study revealed a clear involvement of MTHFR promoter methylation in TAMG, particularly the higher methylation levels in tumor tissue with respect to other tissues. These finding leads us to suppose that it could be involved in mechanisms associated with the development and progression of cancer, especially in the activation of proto-oncogenes. Obviously other studies need to further explore the significance of MTHFR methylation in TAMG, in order to better understand its pathogenic role in the onset of thymomas. The MTHFR protein is also required for the synthesis of DNA precursors, and impairments of this protein could contribute to cancer development by increasing the rate of point mutations and chromosome instability in rapidly dividing cells [12]. We observed a correlation among MTHFR promoter methylation levels in blood, thymic epithelial cells adjacent to the cancer, and thymoma cells that, albeit weak, was statistically significant. Such a correlation could suggest that MTHFR methylation levels in blood might reflect those in other tissues, and might represent a peripheral biomarker of the disease. In this regard, it was observed that females with increased $B R C A 1$ blood methylation have a 3.5-fold increased risk for early-onset breast cancer with histological features commonly seen in tumors arising in women with germline BRCA1 mutations [28]. Similarly, 
glutathione S-transferase 1 (GSTP1) promoter methylation in peripheral DNA is regarded as a potential prognostic marker of prostate cancer [29]. However, as far as MTHFR promoter methylation in the blood is concerned, it should be noted that rather than being a specific marker of a given disease, it could represent a more general biomarker of increased genomic instability. For example, some studies suggest a correlation between hyperhomocysteinemia and MTHFR promoter methylation [26]; others have linked MTHFR promoter methylation in blood cells with markers of chromosome damage, such as an increased frequency of micronuclei [27] or alterations of LINE-1 methylation and stability [15], and there is also indication that MTHFR promoter methylation in blood DNA might reflect dietary B-group vitamin deficiency $[18,30]$ or environmental exposure to cancerous agents, such as those deriving from tobacco smoking [15]. Collectively, those studies suggest that increased MTHFR promoter methylation in blood cells might be a more general marker of impaired one-carbon metabolism and genome instability, rather than a specific disease biomarker.

Another interesting question that still needs to be addressed is how an increased MTHFR promoter methylation could be linked to the regulation of autoimmune-related genes in TAMG patients. For example, it is known that the autoimmune regulator (AIRE) gene is hypomethylated in thymomas, and that both DNA and histone tail methylation marks regulate AIRE expression [31]. Therefore, we speculate that MTHFR methylation contributes to both DNA and histone tail methylation changes; however, this must be demonstrated in subsequent studies.

Regarding the DNMTs, the writers of DNA methylation reactions, in this study only DNMT3A showed increased methylation levels in tumor tissue, comparable to those found in adjacent thymic tissue, with respect to blood; the other two DNMTs genes, DNMT1 and DNMT3B, resulted hypomethylated. The methylation of these genes was not yet investigated in thymomas but a previous study showed that they were overexpressed in the advanced stages of thymic epithelial tumors with respect to early stages [14].

A double role of de novo DNMTs in tumor stages, as oncogenes and tumor suppressor genes, was proposed. In healthy tissues, tumor suppressor genes are unmethylated and oncogenes are methylated. In early tumor stages, DNMTs seem to lead to methylation-associated repression of tumor suppressor genes and to promote tumor initiation, while in advanced tumor stages the downregulation of de novo DNMTs seems to be associated with promoter DNA hypomethylation of specific oncogenes and, consequently, would promote tumorigenesis [32].

In our cohort, DNMT1 and DNMT3B do not show different methylation levels among different tissues, so we cannot hypothesize the involvement of the methylation of these genes in thymoma-associated myasthenia gravis pathogenesis.

Concerning the DNMT3A gene, it shows higher methylation levels in both cancer tissue and adjacent thymic tissue, where almost the same levels have been found with respect to blood, suggesting that its methylation is not connected exclusively with tumor events but already shows alterations in healthy tissue. Aberrant DNMT3A methylation was also observed in other cancers, such as in acute myeloid leukemia [16] and in breast cancer, where DNMT3A expression is associated with advanced stages [17]. Studies performed in mice with conditional knockout of Dnmt3a revealed a role for DNA methylation in mediating the self-renewal and differentiation of normal hematopoietic stem cells and leukemia stem cells [33]. A functional role of this gene in thymic epithelial tumors emerged from studies that focused on mutation analysis, revealing that DNMT3A is one the most frequently mutated genes in thymic carcinoma [34], and that the mutation p.G728D is associated with B3 thymomas [35]. Similarly, a SNP in the promoter of DNMT3B, namely -579G $>$ T, was associated with TAMG [36], overall suggesting a contribution of de novo DNMTs in thymomas.

From the DNA promoter methylation analyses performed in this study, the involvement of MTHFR and DNMT3A methylation in thymoma-associated myasthenia gravis has been proven, even if other studies are needed to assess a potential pathogenic role of these genes in TAMG. Other limitations of the present study that need to be addressed in subsequent investigations include the analysis of gene expression levels of the studied genes in TAMG samples and a comparison study between TAMG 
samples and thymomas obtained from individuals without MG, which could help us to clarify whether the observed methylation changes are TAMG-specific or rather are common in thymomas.

\section{Materials and Methods}

\subsection{Study Population}

A total of $69 \mathrm{AChR}$ positive patients (AChR+) with thymoma (TAMG) were recruited the Myasthenia Clinic (Department of Neuroscience and Cardiac and Thoracic Department, Pisa University Hospital). The diagnosis of myasthenia gravis was made on the clinical symptoms of the patient together with the detection of positivity of AChR antibodies. Clinical stages of MG were assessed according to the Osserman classification. Demographic characteristics of the population are shown in Table 2. DNA samples were obtained from both the surgically resected tumor tissue of 69 patients (Table 2) and from the adjacent normal tissue available from 44 of them. An aliquot of blood in EDTA tubes was also collected from each patient and stored at $-20{ }^{\circ} \mathrm{C}$ until assayed. Each patient gave informed written consent for genotype analysis before blood drawing. The study was conducted in accordance with the Declaration of Helsinki, and the protocol was approved by the Ethics Committee of the Pisa University Hospital (Protocol number 21302/2015).

\subsection{Extraction of Genomic DNA}

Genomic blood and tissue DNA was extracted using QIAmp DNA Mini Kit (Qiagen, Milan, Italy) according to the manufacturer's instruction. The extracted DNA was quantified using a Nano Drop ND 2000c spectrophotometer (NanoDrop, Thermo Scientific, Wilmington, DE, USA).

\subsection{Bisulfite Modification}

Two hundred nanograms of DNA from each sample were treated with sodium bisulfite using the EpiTectH Bisulfite Kit (Qiagen) according to the manufacturer's protocol. Sodium bisulfite treatment converts all unmethylated cytosines into uracil, while methylated cytosines are left unchanged.

\subsection{Methylation-Sensitive-High-Resolution Melting (MS-HRM) Analysis}

Promoter methylation was assessed by means of methylation-sensitive-high-resolution melting (MS-HRM) analysis in a CFX96 Real-Time PCR detection system (Bio-Rad, Milan, Italy). For the MS-HRM analysis we developed protocols according to the literature [37,38]. All analyses were run according to the following conditions: one cycle of $95^{\circ} \mathrm{C}$ for $12 \mathrm{~min}, 60$ cycles of $95{ }^{\circ} \mathrm{C}$ for $30 \mathrm{~s}, \mathrm{~T}_{\mathrm{a}}$ for $30 \mathrm{~s}$ and $72{ }^{\circ} \mathrm{C}$ for $15 \mathrm{~s}$; followed by an HRM step of $95{ }^{\circ} \mathrm{C}$ for $10 \mathrm{~s}$ and $50{ }^{\circ} \mathrm{C}$ for $1 \mathrm{~min}, 65^{\circ} \mathrm{C}$ for $15 \mathrm{~s}$, and continuous acquisition to $95{ }^{\circ} \mathrm{C}$ at one acquisition per $0.2^{\circ} \mathrm{C}$. PCR was performed in a final volume of $25 \mu \mathrm{L}$, containing $12.5 \mu \mathrm{L}$ of master mix (Qiagen), 10 pmol of each primer, and $10 \mathrm{ng}$ of bisulfite-modified DNA template. Each reaction was performed in duplicate. We analyzed $10 \%$ of the samples independently on separate occasions to verify the inter-assay variability and observed good reproducibility. Table 3 shows the conditions used for each gene, such as primers, annealing temperature, $\mathrm{CpG}$ sites, and amplicon length; for MTHFR and DNMT3A we used primers derived from the literature $[15,16]$, while $D N M T 1$ and $D N M T 3 B$ primers were designed by us using the Meth-primer program (available at http://www.urogene.org/methprimer). Fully methylated and unmethylated DNA (EpiTectH methylated and unmethylated human control DNA, bisulfite converted, Qiagen) were mixed to obtain the following ratios of methylation: $0 \%, 12.5 \%, 25 \%, 50 \%, 75 \%$, and $100 \%$. Standard curves with known methylation ratios were included in each assay and were used to deduce the methylation ratio of each blood, adjacent healthy tissue, and tumor tissue. Validation of the MS-HRM assays was performed by means of pyrosequencing, as detailed elsewhere [26]. In order to obtain single methylation percentage values from MS-HRM assays, we applied an interpolation method developed and described by us, which allowed us to obtain precise HRM methylation values comparable to those obtained by pyrosequencing [37]. 
Table 2. Demographic and clinico-pathological characteristics of the studied population (TAMG: thymoma-associated myasthenia gravis, MG: myasthenia gravis, F: females, M: males, NS: no specified tumor histology).

\begin{tabular}{|c|c|c|c|c|c|c|}
\hline No. TAMG Patients & Age \pm SD & Gender $(\%)$ & MG Onset (\%) & MG Osserman Classification (\%) & Thymoma Histology (\%) & Masaoka Stage (\%) \\
\hline 69 & $55.5 \pm 13.2$ & $\begin{array}{l}\text { F: } 37(54) \\
\text { M: } 32(46)\end{array}$ & $\begin{array}{l}<50 \text { years: } 26(38) \\
\geq 50 \text { years: } 43(62)\end{array}$ & $\begin{array}{l}\text { I: } 7(10.0) \\
\text { IIA: } 11(16.0) \\
\text { IIB: } 34(49.5) \\
\text { III: } 13(19.0) \\
\text { IV: } 3(4.0) \\
\text { V: } 1(1.5) \\
-\end{array}$ & $\begin{array}{c}\text { A: } 13(18.8) \\
\text { AB: } 13(18.8) \\
\text { B1: } 5(7.2) \\
\text { B2: } 23(33.4) \\
\text { B3: } 8(11.6) \\
\text { B2-B3: } 5(7.2) \\
\text { NS: } 2(3.0)\end{array}$ & $\begin{array}{l}\text { I: } 7(10) \\
\text { IIa: } 15(22) \\
\text { IIb: } 29(42) \\
\text { III: } 7 \text { (10) } \\
\text { IVa: } 9 \text { (13) } \\
\text { NS: } 2 \text { (3) } \\
-\end{array}$ \\
\hline
\end{tabular}

Table 3. Primer sequences and annealing temperatures $\left(\mathrm{T}_{\mathrm{a}}\right)$ used during MS-HRM analysis, amplicon length, number of CpG sites for each gene, accession number, and amplified region ( ${ }^{*}$ DMR2: differentially methylated region = upstream promoter region involved in the regulation of transcript 2 of $D N M T 3 A$ gene, details are provided in [16]).

\begin{tabular}{|c|c|c|c|c|c|c|}
\hline Gene & Primer Sequences & $T_{a}$ & Amplicon Length & CpG Sites & Accession Number & Amplified Region \\
\hline MTHFR & $\begin{array}{l}\text { F 5'-TTTTAATTTTTGTTTGGAGGGTAGT-3' } \\
\text { R 5'-AAAAAAACCACTTATCACCAAATTC-3' }\end{array}$ & $54^{\circ}$ & $155 \mathrm{bp}$ & 7 & NM_005957.4 & from +30 to $+184 \mathrm{bp}$ \\
\hline DNMT1 & $\begin{array}{l}\text { F 5'-GGTATCGTGTTTATTTTTTAGTAA-3' } \\
\text { R 5'-ACGAAACCAACCATACCCAA-3' }\end{array}$ & $52^{\circ}$ & $114 \mathrm{bp}$ & 9 & NG_028016.3 & from -106 to $+8 \mathrm{bp}$ \\
\hline DNMT3A & $\begin{array}{l}\text { F 5'-GGTTTGGGTTTATTGTAGGAAGGTTATTAAGGT-3' } \\
\text { R 5'-AATCCAAAACCCCCCTATCACGAAA-3' }\end{array}$ & $58^{\circ}$ & $199 \mathrm{bp}$ & 7 & NM_153759.3 & DMR2 * \\
\hline DNMT3B & $\begin{array}{l}\text { F 5'-TGGTGTTGTGTGATTATAGTGG-3' } \\
\text { R 5'-TCACCCTAAAAAATCAAAAACC-3' }\end{array}$ & $55^{\circ}$ & $174 \mathrm{bp}$ & 6 & NG_007290.1 & from -397 to $-223 b p$ \\
\hline
\end{tabular}




\subsection{Statistical Analysis}

Differences in mean methylation levels among the three groups were evaluated with a Student's $t$-test for paired samples. The effect of clinical and pathological features, such as onset of MG (early or late), MG Osserman classification, and thymoma histology, on mean methylation levels was assessed by means of analysis of variance (ANOVA), including age at sampling and gender as covariates. Linear regression analysis was performed to search for a correlation between age and methylation levels in the studied tissues, as well as to search for a correlation of MTHFR methylation levels among the different tissues. Analyses were performed with the STATGRAPHICS 5.1 Plus software package for Windows. Since we studied four different genes in our cohort, a Bonferroni's correction for multiple comparisons was applied, and the cut-off $p$-value for considering a result to be statistically significant was set at $0.05 / 4=0.0125$. The statistical power of the study was evaluated with the clinical tool and calculators for medical professionals, ClinCalc (Available at http://clincalc.com/Stats/Power.aspx). The sample size was chosen to have an a priori power of $>80 \%$ to detect mean methylation differences of $5 \%$ or higher.

\section{Conclusions}

In conclusion, the present study revealed increased MTHFR promoter methylation in thymomas obtained from MG patients and some degrees of methylation of the DNMT3A gene in thymic tissue with respect to blood were observed. Other studies supported by gene expression analysis are needed to assess a potential pathogenic role of these genes in TAMG.

Supplementary Materials: Supplementary materials can be found at www.mdpi.com/1422-0067/17/12/2121/s1.

Acknowledgments: The study was supported by researcher's intramural funds; additional support was provided by “Associazione MIA Onlus (Associazione Italiana Miastenia Onlus)”.

Author Contributions: Angela Lopomo performed the experiments and wrote the manuscript; Roberta Ricciardi, Michelangelo Maestri, and Anna De Rosa clinically characterized myasthenia gravis patients and provided blood samples; Franca Melfi, Marco Lucchi, and Alfredo Mussi characterized and provided thymic specimens from myasthenia gravis patients; Fabio Coppedè and Lucia Migliore conceived and designed the study, provided reagents, materials, and statistical advice, and critically reviewed the entire manuscript.

Conflicts of Interest: The authors declare no conflict of interest.

\section{References}

1. Marx, A.; Ströbel, P.; Badve, S.S.; Chalabreysse, L.; Chan, J.K.; Chen, G.; de Leval, L.; Detterbeck, F.; Girard, N.; Huang, J.; et al. ITMIG consensus statement on the use of the WHO histological classification of thymoma and thymic carcinoma: Refined definitions, histological criteria, and reporting. J. Thorac. Oncol. 2014, 9, 596-611. [CrossRef] [PubMed]

2. Ried, M.; Marx, A.; Götz, A.; Hamer, O.; Schalke, B.; Hofmann, H.S. State of the art: Diagnostic tools and innovative therapies for treatment of advanced thymoma and thymic carcinoma. Eur. J. Cardiothorac. Surg. 2016, 49, 1545-1552. [CrossRef] [PubMed]

3. Melzer, N.; Ruck, T.; Fuhr, P.; Gold, R.; Hohlfeld, R.; Marx, A.; Melms, A.; Tackenberg, B.; Schalke, B.; Schneider-Gold, C.; et al. Clinical features, pathogenesis, and treatment of myasthenia gravis: A supplement to the guidelines of the German neurological society. J. Neurol. 2016, 263, 1473-1494. [CrossRef] [PubMed]

4. Marx, A.; Porubsky, S.; Belharazem, D.; Saruhan-Direskeneli, G.; Schalke, B.; Ströbel, P.; Weis, C.A. Thymoma related myasthenia gravis in humans and potential animal models. Exp. Neurol. 2015, 270, 55-65. [CrossRef] [PubMed]

5. Rajan, A.; Girard, N.; Marx, A. State of the art of genetic alterations in thymic epithelial tumors. J. Thorac. Oncol. 2014, 9, S131-S136. [CrossRef] [PubMed]

6. Jones, P.A. Functions of DNA methylation: Islands, start sites, gene bodies and beyond. Nat. Rev. Genet. 2012, 13, 484-492. [CrossRef] [PubMed]

7. Ivanov, M.; Barragan, I.; Ingelman-Sundberg, M. Epigenetic mechanisms of importance for drug treatment. Trends Pharmacol. Sci. 2014, 35, 384-396. [CrossRef] [PubMed] 
8. Chen, C.; Yin, N.; Yin, B.; Lu, Q. DNA methylation in thoracic neoplasms. Cancer Lett. 2011, 301, 7-16. [CrossRef] [PubMed]

9. Suzuki, M.; Chen, H.; Shigematsu, H.; Ando, S.; Iida, T.; Nakajima, T.; Fujisawa, T.; Kimura, H. Aberrant methylation: Common in thymic carcinomas, rare in thymomas. Oncol. Rep. 2005, 14, 1621-1624. [CrossRef] [PubMed]

10. Hirabayashi, H.; Fujii, Y.; Sakaguchi, M.; Tanaka, H.; Yoon, H.E.; Komoto, Y.; Inoue, M.; Miyoshi, S.; Matsuda, H. p16INK4, pRB, p53 and cyclin D1 expression and hypermethylation of CDKN2 gene in thymoma and thymic carcinoma. Int. J. Cancer 1997, 73, 639-644. [CrossRef]

11. Mokhtar, M.; Kondo, K.; Namura, T.; Ali, A.H.; Fujita, Y.; Takai, C.; Takizawa, H.; Nakagawa, Y.; Toba, H.; Kajiura, K.; et al. Methylation and expression profiles of MGMT gene in thymic epithelial tumors. Lung Cancer 2014, 83, 279-287. [CrossRef] [PubMed]

12. Coppedè, F. Epigenetic biomarkers of colorectal cancer: Focus on DNA methylation. Cancer Lett. 2014, 342, 238-247. [CrossRef] [PubMed]

13. Nazki, F.H.; Sameer, A.S.; Ganaie, B.A. Folate: Metabolism, genes, polymorphisms and the associated diseases. Gene 2014, 533, 11-20. [CrossRef] [PubMed]

14. Chen, C.; Yin, B.; Wei, Q.; Li, D.; Hu, J.; Yu, F.; Lu, Q. Aberrant DNA Methylation in Thymic Epithelial Tumors. Cancer Investig. 2009, 27, 582-591. [CrossRef] [PubMed]

15. Vaissière, T.; Hung, R.J.; Zaridze, D.; Moukeria, A.; Cuenin, C.; Fasolo, V.; Ferro, G.; Paliwal, A.; Hainaut, P.; Brennan, P.; et al. Quantitative analysis of DNA methylation profiles in lung cancer identifies aberrant DNA methylation of specific genes and its association with gender and cancer risk factors. Cancer Res. 2009, 69, 243-252. [CrossRef] [PubMed]

16. Jost, E.; Lin, Q.; Weidner, C.I.; Wilop, S.; Hoffmann, M.; Walenda, T.; Schemionek, M.; Herrmann, O.; Zenke, M.; Brümmendorf, T.H.; et al. Epimutations mimic genomic mutations of DNMT3A in acute myeloid leukemia. Leukemia 2014, 28, 1227-1234. [CrossRef] [PubMed]

17. Santos, G.C.; da Silva, A.P.; Feldman, L.; Ventura, G.M.; Vassetzky, Y.; de Moura Gallo, C.V. Epigenetic modifications, chromatin distribution and TP53 transcription in a model of breast cancer progression. J. Cell. Biochem. 2015, 116, 533-541. [CrossRef] [PubMed]

18. Wei, L.K.; Sutherland, H.; Au, A.; Camilleri, E.; Haupt, L.M.; Gan, S.H.; Griffiths, L.R. A potential epigenetic marker mediating serum folate and vitamin B12 levels contributes to the risk of ischemic stroke. BioMed Res. Int. 2015, 2015, 167976. [PubMed]

19. Ghattas, M.; El-Shaarawy, F.; Mesbah, N.; Abo-Elmatty, D. DNA methylation status of the methylenetetrahydrofolate reductase gene promoter in peripheral blood of end-stage renal disease patients. Mol. Biol. Rep. 2014, 41, 683-688. [CrossRef] [PubMed]

20. Khazamipour, N.; Noruzinia, M.; Fatehmanesh, P.; Keyhanee, M.; Pujol, P. MTHFR promoter hypermethylation in testicular biopsies of patients with non-obstructive azoospermia: The role of epigenetics in male infertility. Hum. Reprod. 2009, 24, 2361-2364. [CrossRef] [PubMed]

21. Wu, W.; Shen, O.; Qin, Y.; Niu, X.; Lu, C.; Xia, Y.; Song, L.; Wang, S.; Wang, X. Idiopathic male infertility is strongly associated with aberrant promoter methylation of methylenetetrahydrofolate reductase (MTHFR). PLoS ONE 2010, 5, e13884. [CrossRef] [PubMed]

22. Rotondo, J.C.; Bosi, S.; Bazzan, E.; di Domenico, M.; de Mattei, M.; Selvatici, R.; Patella, A.; Marci, R.; Tognon, M.; Martini, F. Methylenetetrahydrofolate reductase gene promoter hypermethylation in semen samples of infertile couples correlates with recurrent spontaneous abortion. Hum. Reprod. 2012, 27, 3632-3638. [CrossRef] [PubMed]

23. Ge, J.; Wang, J.; Zhang, F.; Diao, B.; Song, Z.F.; Shan, L.L.; Wang, W.; Cao, H.J.; Li, X.Q. Correlation between MTHFR gene methylation and pre-eclampsia, and its clinical significance. Genet. Mol. Res. 2015, 14, 8021-8028. [CrossRef] [PubMed]

24. Botezatu, A.; Socolov, D.; Iancu, I.V.; Huica, I.; Plesa, A.; Ungureanu, C.; Anton, G. Methylenetetrahydrofolate reductase (MTHFR) polymorphisms and promoter methylation in cervicaloncogenic lesions and cancer. J. Cell. Mol. Med. 2013, 17, 543-549. [CrossRef] [PubMed]

25. Mani, S.; Szymańska, K.; Cuenin, C.; Zaridze, D.; Balassiano, K.; Lima, S.C.; Matos, E.; Daudt, A.; Koifman, S.; Filho, V.W.; et al. DNA methylation changes associated with risk factors in tumors of the upper aerodigestive tract. Epigenetics 2012, 7, 270-277. [CrossRef] [PubMed] 
26. Tannorella, P.; Stoccoro, A.; Tognoni, G.; Petrozzi, L.; Salluzzo, M.G.; Ragalmuto, A.; Siciliano, G.; Haslberger, A.; Bosco, P.; Bonuccelli, U.; et al. Methylation analysis of multiple genes in blood DNA of Alzheimer's disease and healthy individuals. Neurosci. Lett. 2015, 600, 143-147. [CrossRef] [PubMed]

27. Coppedè, F.; Denaro, M.; Tannorella, P.; Migliore, L. Increased MTHFR promoter methylation in mothers of Down syndrome individuals. Mutat. Res. 2016, 787, 1-6. [CrossRef] [PubMed]

28. Wong, E.M.; Southey, M.C.; Fox, S.B.; Brown, M.A.; Dowty, J.G.; Jenkins, M.A.; Giles, G.G.; Hopper, J.L.; Dobrovic, A. Constitutional methylation of the BRCA1 promoter is specifically associated with BRCA1 mutation-associated pathology in early-onset breast cancer. Cancer Prev. Res. 2011, 4, 23-33. [CrossRef] [PubMed]

29. Mahon, K.L.; Qu, W.; Devaney, J.; Paul, C.; Castillo, L.; Wykes, R.J.; Chatfield, M.D.; Boyer, M.J.; Stockler, M.R.; Marx, G.; et al. Methylated Glutathione S-transferase 1 (mGSTP1) is a potential plasma free DNA epigenetic marker of prognosis and response to chemotherapy in castrate-resistant prostate cancer. Br. J. Cancer 2014, 111, 1802-1809. [CrossRef] [PubMed]

30. Grossi, E.; Stoccoro, A.; Tannorella, P.; Migliore, L.; Coppedè, F. Artificial neural networks link one-carbon metabolism to gene-promoter methylation in Alzheimer's disease. J. Alzheimers Dis. 2016, 53, 1517-1522. [CrossRef] [PubMed]

31. Kont, V.; Murumägi, A.; Tykocinski, L.O.; Kinkel, S.A.; Webster, K.E.; Kisand, K.; Tserel, L.; Pihlap, M.; Ströbel, P.; Scott, H.S.; et al. DNA methylation signatures of the AIRE promoter in thymic epithelial cells, thymomas and normal tissues. Mol. Immunol. 2011, 49, 518-526. [CrossRef] [PubMed]

32. Fernandez, A.F.; Huidobro, C.; Fraga, M.F. De novo DNA methyltransferases: Oncogenes, tumor suppressors, or both? Trends Genet. 2012, 28, 474-479. [CrossRef] [PubMed]

33. Mayle, A.; Yang, L.; Rodriguez, B.; Zhou, T.; Chang, E.; Curry, C.V.; Challen, G.A.; Li, W.; Wheeler, D.; Rebel, V.I.; et al. Dnmt3a loss predisposes murine hematopoietic stem cells to malignant transformation. Blood 2015, 125, 629-638. [CrossRef] [PubMed]

34. Wang, Y.; Thomas, A.; Lau, C.; Rajan, A.; Zhu, Y.; Killian, J.K.; Petrini, I.; Pham, T.; Morrow, B.; Zhong, X.; et al. Mutations of epigenetic regulatory genes are common in thymic carcinomas. Sci. Rep. 2014, 4, 7336. [CrossRef] [PubMed]

35. Belani, R.; Oliveira, G.; Erikson, G.A.; Ra, S.; Schechter, M.S.; Lee, J.K.; Shipman, W.J.; Haaser, S.M.; Torkamani, A. ASXL1 and DNMT3A mutation in a cytogenetically normal B3 thymoma. Oncogenesis 2014, 3, e111. [CrossRef] [PubMed]

36. Coppedè, F.; Ricciardi, R.; Denaro, M.; de Rosa, A.; Provenzano, C.; Bartoccioni, E.; Baggiani, A.; Lucchi, M.; Mussi, A.; Migliore, L. Association of the DNMT3B -579G > T polymorphism with risk of thymomas in patients with myasthenia gravis. PLoS ONE 2013, 8, e80846. [CrossRef] [PubMed]

37. Migheli, F.; Stoccoro, A.; Coppedè, F.; Omar, W.A.; Failli, A.; Consolini, R.; Seccia, M.; Spisni, R.; Miccoli, P.; Mathers, J.C.; et al. Comparison study of MS-HRM and pyrosequencing techniques for quantification of APC and CDKN2A gene methylation. PLoS ONE 2013, 8, e52501. [CrossRef] [PubMed]

38. Coppedè, F.; Migheli, F.; Lopomo, A.; Failli, A.; Legitimo, A.; Consolini, R.; Fontanini, G.; Sensi, E.; Servadio, A.; Seccia, M.; et al. Gene promoter methylation in colorectal cancer and healthy adjacent mucosa specimens: Correlation with physiological and pathological characteristics, and with biomarkers of one-carbon metabolism. Epigenetics 2014, 9, 621-633. [CrossRef] [PubMed]

(C) 2016 by the authors; licensee MDPI, Basel, Switzerland. This article is an open access article distributed under the terms and conditions of the Creative Commons Attribution (CC-BY) license (http://creativecommons.org/licenses/by/4.0/). 